مطالعه تأثير زمان برداشت، تيمارهاى غيرسمى و دماى انبار بر ماندگارى بس از برداشت ليموآب Citrus aurantifolia L. ليرسي

\author{
على حاتمى 'و عبدالحسين ابوطالبى جهرمى ب* \\ (تاريخ دريافت: 9V/N/19 1 ؛ تاريخ يذيرش: 99/19/19 )
}

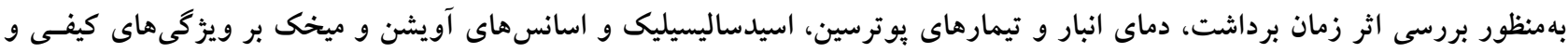

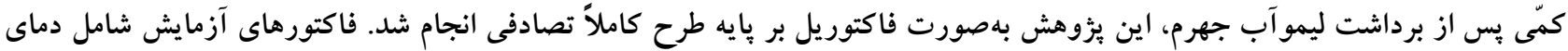

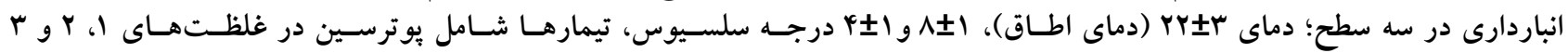

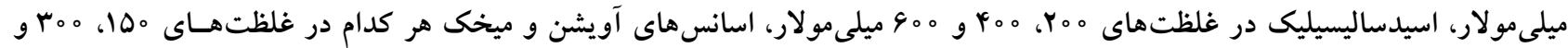

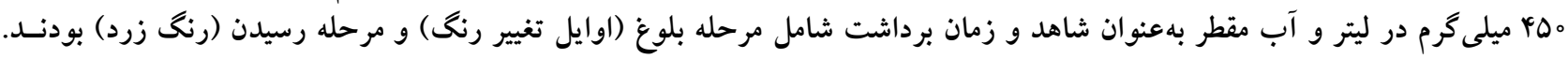

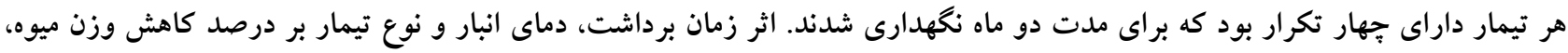

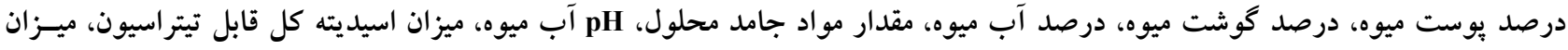

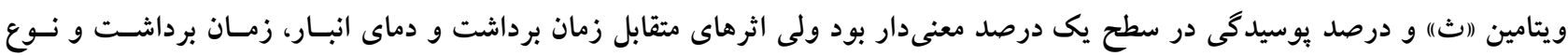

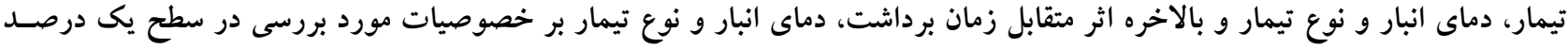

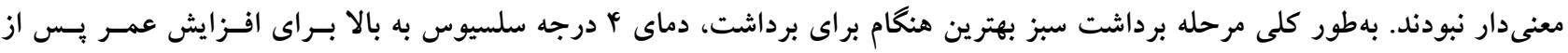

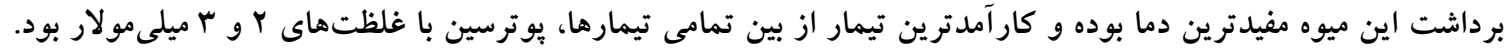

وازههاى كليدى: ليمو آب، بس از برداشت، ساليسيليكاسيد، يوترسين، اسانس گياهى

ا و r. به ترتيب دانشجوى كارشناسى ارشد و دانشيار، كروه علوم باغبانى، واحد جهرم، دانشكاه آزاد اسلامى، جهرم، ايران.

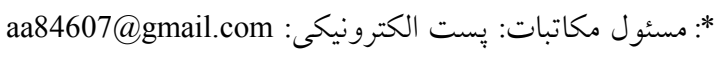


مصرف كننده قرار مى گيرد (9).

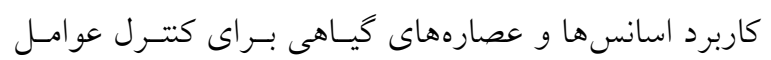

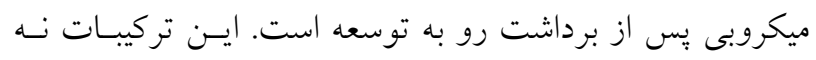

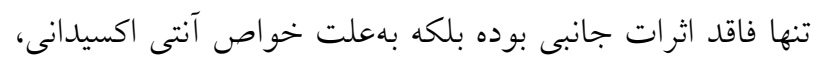

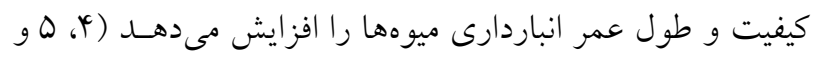

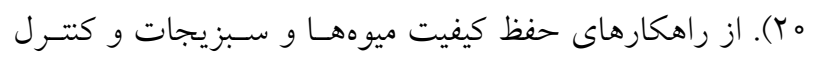

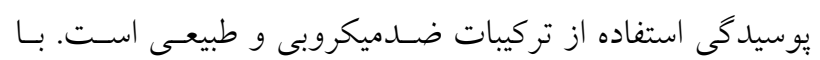

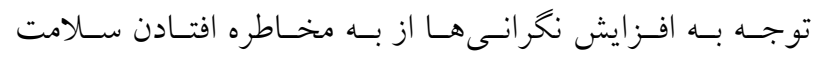

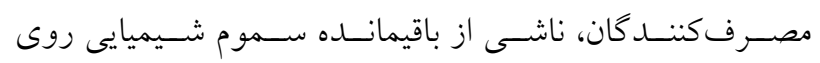

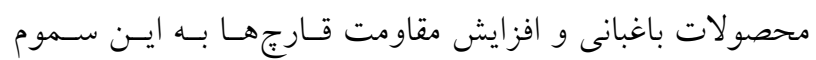

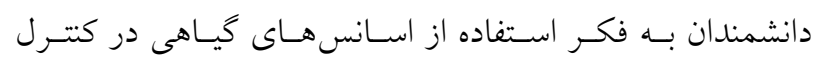

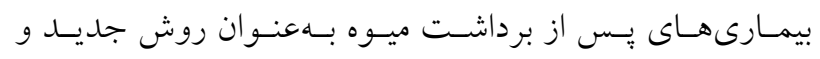

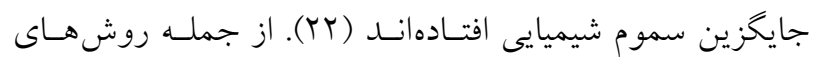

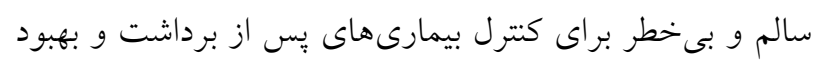

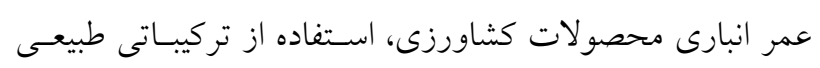

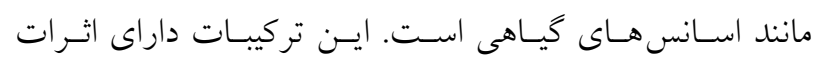

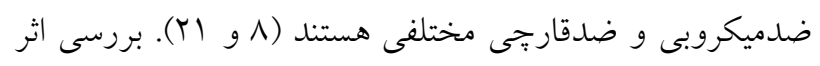

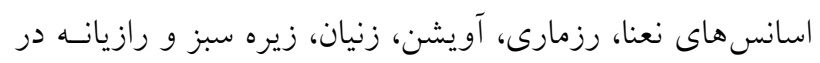

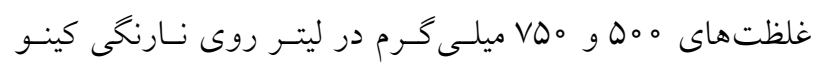

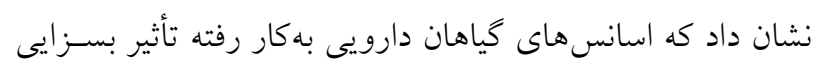

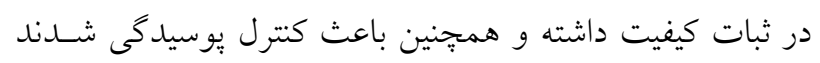

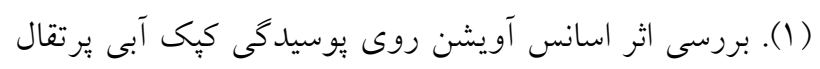

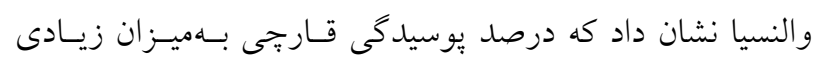

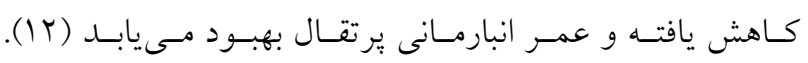

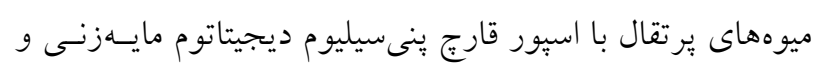

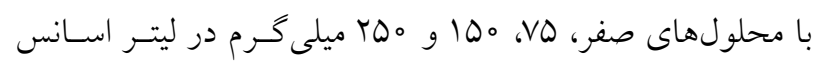

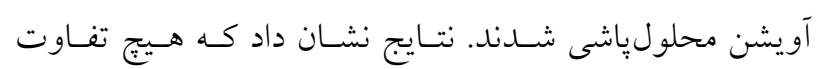

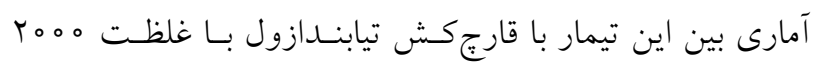

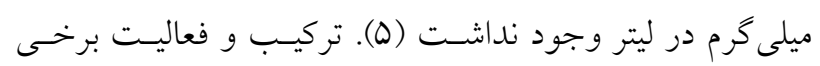

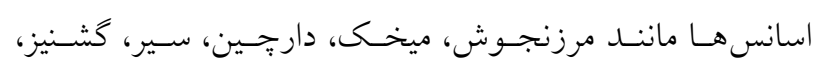

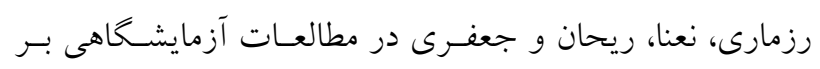
فعاليت هاى ضدميكروبى كزارش شده و اثرات ضدميكروبى آنها

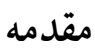
يكى راهكار موثر براى افـزايش مانـــارى ميـوه كـهـ بـهـ دسـت

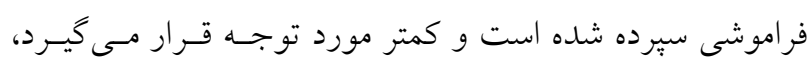

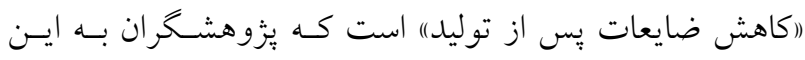
بخش، اصـطلاح (برداشـت مخفـى" را اختصـاص دادهانــ (1).

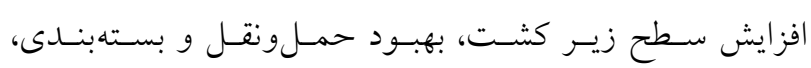

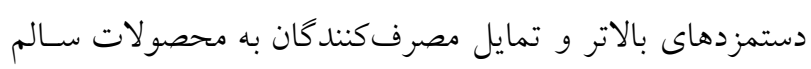

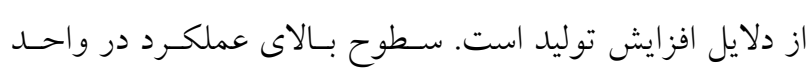

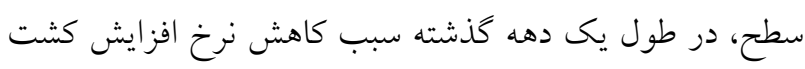

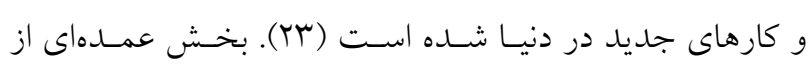

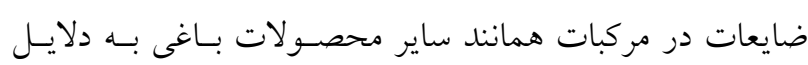

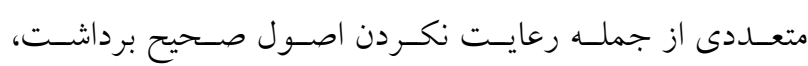

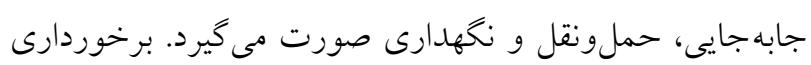

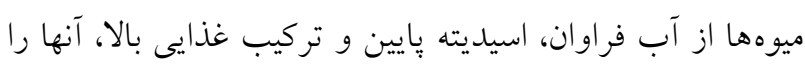
نسبت به حمله بيماركرهاى مختلف مستعد مى كند، لذا با اعمال

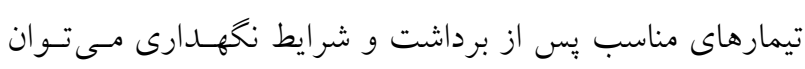
ماندكارى و كيفيت محصول در طول مدت انباردارى را بهطبور

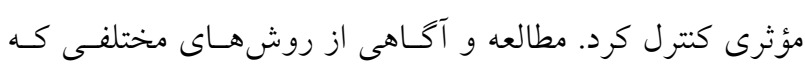

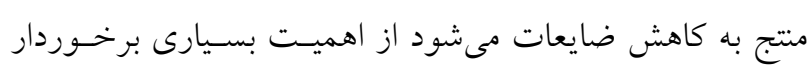

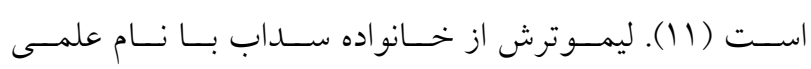

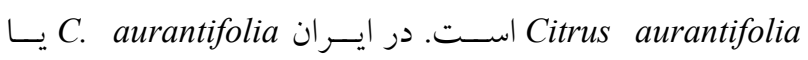

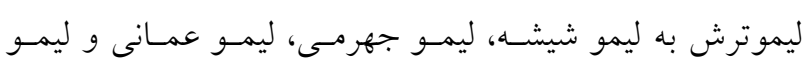

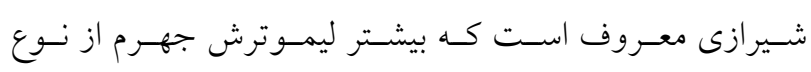
Mexican lime تلفات يس از برداشت به دو گروه اصلى تقسـيم مسى شــوند:

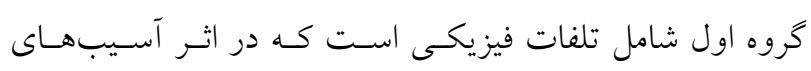

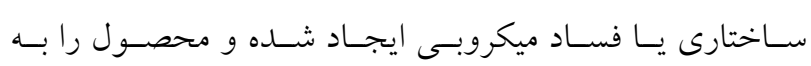

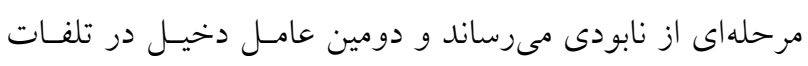

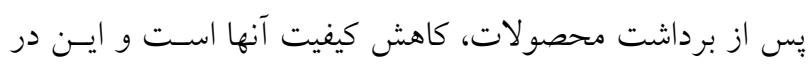
اثر تغييرات فيزيولوزيكى و نيز تغيير در تركيبات شيميايى درون

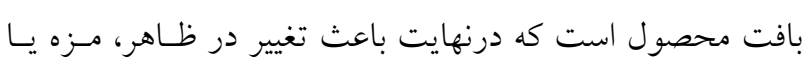

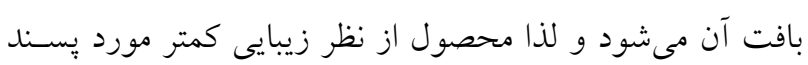


ميوه (رنخ ميوه سـبز تيـره تـا سـبز روشـن و رنــى ميـوه زرد

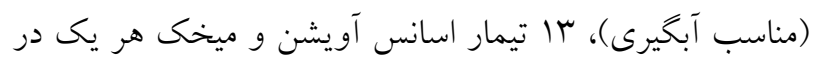

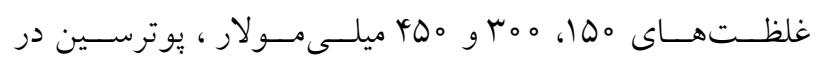

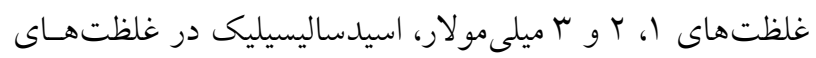

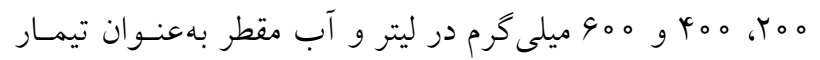

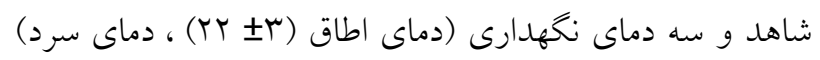

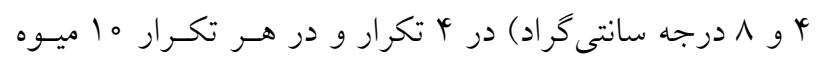
بود. برداشت ميوه در هر مرحله با قيجى باغبـانى انجـام شـد و قبل از اعمال تيمار اطلاعات مربوط به وزن ميوه براى هر تكرار با ترازوى دو صفر مشخص شد، تيمارها بهصورت غوطـهورى

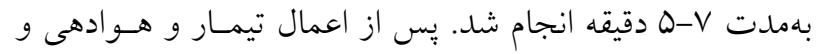

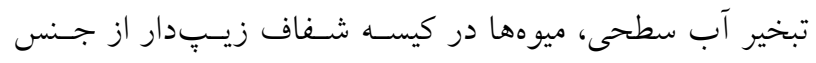

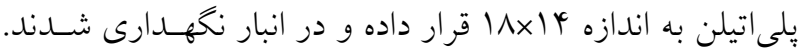

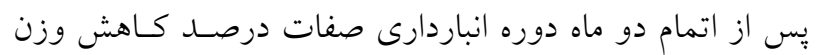

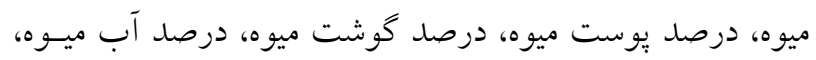

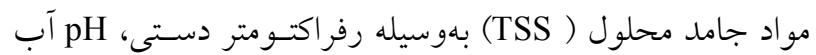

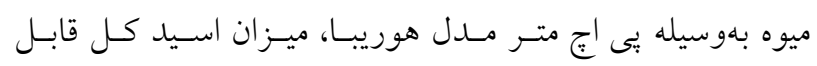

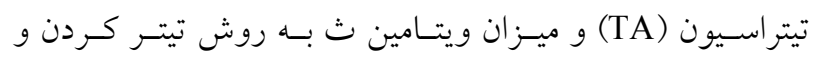

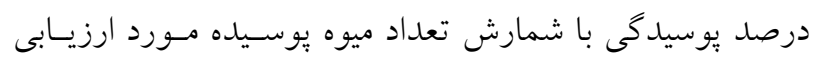

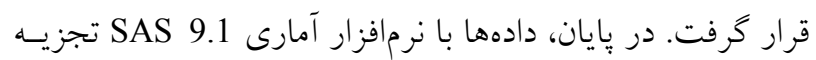

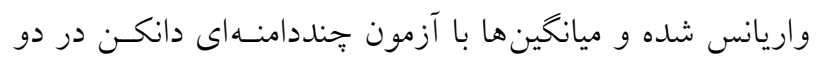
سطح ينج درصد و يك درصد با هم مقايسه شدند.

\section{نتايج و بحث} تجزيه واريانس دادهها بر اساس نتايج تجزيه واريانس براى همه صفات مورد بررسى،

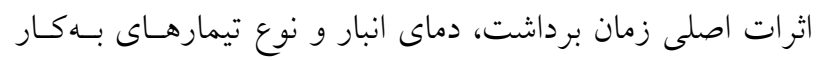

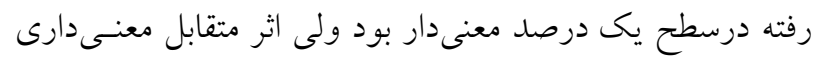
بين آنها وجود نداشت (جدول (1).

درصد كاهش وزن ميوه نوبت اول برداشت نسبت به نوبت دوم برداشت از نظـر درصـد
در برابر ياتوزنهاى مواد غذايى و عوامل فساد به اثبـات رسـيده است همجزنين اثر ضدباكتريايى برخى اسـانسهـا در كـاهو نيـز بررسى شده است (r و و (T).

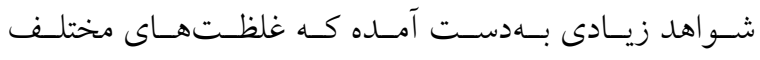
اسيدساليسيليك و مدت زمان تأثير گذارى آن واكنشهاى متعددى را در كياه سبب مىشود. اسيدساليسيليك بـهــــوان يـك تركيـب طبيعى، بازدارنده تبديل ACC به اتيلن نيـز اسـت (Y ا و فT). اثـر مفيد اسيدساليسيليك در جلـو گيرى از بوسـيدگى در طـول دوره انباردارى در هلو (ب)، توت فرنكى (צ) و انخور (YY) و بهعنوان يك تركيب طبيعى و غيرمضر براى انسان با قابليت بسـيار بـالا در كاهش توليد اتيلن گزارش شده است (YO). يلى آمينها يك كروه جديد از تنظيم كنندهاى رشـد گيـاهى هستند و بززوهشها نشان دادهاند كه كاربرد خارجى يلى آمينهـا بر ويززى هاى مختلف كيفـى ميـوه مانــــ سـفتى بافـت، ميـزان

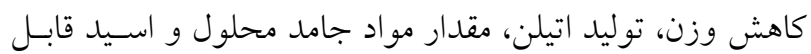
تيتر اسيون تأثير گذار است (Y)). در يززوهشى نشان داده شـد كـه يلى آمين ها بهعنوان كاتيونهاى آلى همانند كـاتيونهـاى غير آلى لى مثـل كلريـــ كلسـيم و آهـن، فعاليـت آنـزيم بـكتـين اسـتراز را

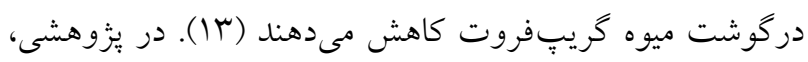
كاربرد بـرونزاى بوترسـين و اسـيرميدين روى نـارنكى باعـث كاهش توليد اتسيلن، تــأخير در نـرم شــن، حفـظ اسـيد كـل و جلو گيرى از افزايش ماده خشك و مواد جامد محلول شد (YN). از آنجا كه ليموآب بهدليل نازكى يوسـت و اسـيد بـالا عمـر انبارمانى كوتاهى دارد، اين ئزوهش با هــف بررسـى اتـر مـواد

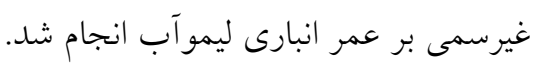

\section{مواد و روشها - (- ماد}

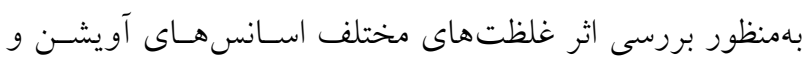

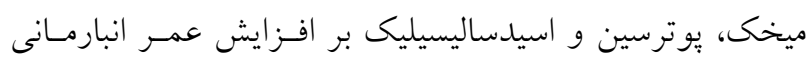

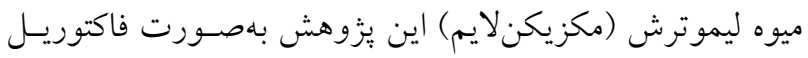

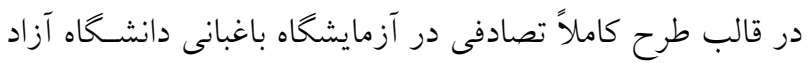

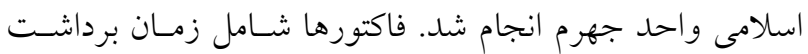




\begin{tabular}{|c|c|c|c|c|c|c|c|c|c|c|}
\hline & & & & Sربعات Sر & ميانخي & & & & \multirow{3}{*}{ D.F } & \multirow{3}{*}{$\begin{array}{c}\text { منابع تغيير } \\
\text { S.V }\end{array}$} \\
\hline ميوه & كوشت & يوست & اسيد كل & \multirow[t]{2}{*}{$\mathrm{pH}$} & \multirow[t]{2}{*}{ TSS } & \multirow{2}{*}{ ويتامين ث } & كاهش & يوسيدگى & & \\
\hline & (درصد) & & $(\mathrm{mg} / 100 \mathrm{cc})$ & & & & \multicolumn{2}{|c|}{ (درصد) } & & \\
\hline $1190 \% 0^{* *}$ & rD৭\&/1 ** & $9 \Psi / \mathbb{C}^{* * *}$ & $r / 19^{* *}$ & $\Gamma / ノ \circ \Delta^{* *}$ & $1 \circ N / 0^{* *}$ & $r \mathcal{G V} / \Lambda^{* *}$ & $900 \mathrm{r} / \mu^{* * *}$ & $90 \cdot 4 / \Lambda^{* *}$ & 1 & زمان برداشت (A) \\
\hline$\Lambda \varphi_{\circ} / \Gamma^{* *}$ & rrVG/9** & $1.94 \% 0^{* * *}$ & $|r /| 0^{* *}$ & $9 / 090^{* *}$ & $194 / 0^{* *}$ & INOY / $\wedge^{* *}$ & $r 9991 / K^{* *}$ & r9909/9** & r & دماى انبار (B) \\
\hline$r V Q / o^{* *}$ & $\Lambda \Delta \mathcal{Y} / \Gamma^{* *}$ & $\Lambda \mathrm{V} / \mathrm{C}^{* *}$ & $V / \Lambda r^{* *}$ & $1 / \circ r \Delta^{* *}$ & $0 / 1^{* *}$ & $\mid r V / 9^{* *}$ & $|r| r / Q^{* *}$ & IYYN/A** & ir & تيمار (C) \\
\hline $\mid N / q^{n s}$ & $r / \Psi^{\text {ens }}$ & $y / o^{\mathrm{ns}}$ & $\circ / / \mathrm{kns}$ & $\circ / \circ \gamma^{\mathrm{ns}}$ & $0 / 9^{\text {ns }}$ & $\boldsymbol{Y} / \mathrm{A}^{\mathrm{ns}}$ & $10 / 0^{\mathrm{ns}}$ & $\mid x / q^{n s}$ & r & AB ثرمتقابل \\
\hline $10 / \mathrm{V}^{\mathrm{ns}}$ & $r / /^{\text {ns }}$ & $r / v^{n s}$ & $\circ / / \Lambda^{\mathrm{ns}}$ & $\circ / \% \circ \psi^{n s}$ & $\circ / \mu^{\mathrm{ns}}$ & $\Delta / 1^{\mathrm{ns}}$ & $14 / 4 n$ & $11 / 0^{\mathrm{ns}}$ & ir & AC ترمتقابل \\
\hline $14 / \mathrm{Vns}^{\mathrm{ns}}$ & $T / V^{\mathrm{ns}}$ & $T / T^{\mathrm{ns}}$ & $\circ / Y_{\circ} \mathrm{ns}$ & $\circ \% \circ Y^{n s}$ & $\circ / T^{\mathrm{ns}}$ & r/ons & $\mathrm{IV} / \mathrm{V}^{\mathrm{ns}}$ & $\mid \Lambda / \psi^{\mathrm{ns}}$ & ry & BC ثترمتقابل \\
\hline $1 \mathrm{y} / \mathrm{V}^{\mathrm{ns}}$ & $r / r^{n s}$ & $r / \Lambda^{n s}$ & $\circ / 1 Q^{\mathrm{ns}}$ & $\circ / \circ \circ y^{\mathrm{cns}}$ & $\circ / \mathbb{K}^{\mathrm{ns}}$ & $r / q^{\text {ns }}$ & $|N /|^{\mathrm{ns}}$ & $\mathrm{V} / \mathrm{o}^{\mathrm{ns}}$ & TY & ABC اثرمتقابل \\
\hline$I T / V$ & $T / \Lambda$ & $\mathrm{T} / \Lambda$ & $\circ / 10$ & \%००Y & $0 / 4$ & $\Delta / r$ & $10 / 9$ & $19 / 9$ & thy & خطا \\
\hline $11 / 0$ & $T / Y$ & $9 / 0$ & $Q / \circ$ & $1 / 9$ & $9 / 0$ & $V / 9$ & $10 / 9$ & $11 / \pi$ & $(\%$ & ضريب تغييرات \\
\hline
\end{tabular}

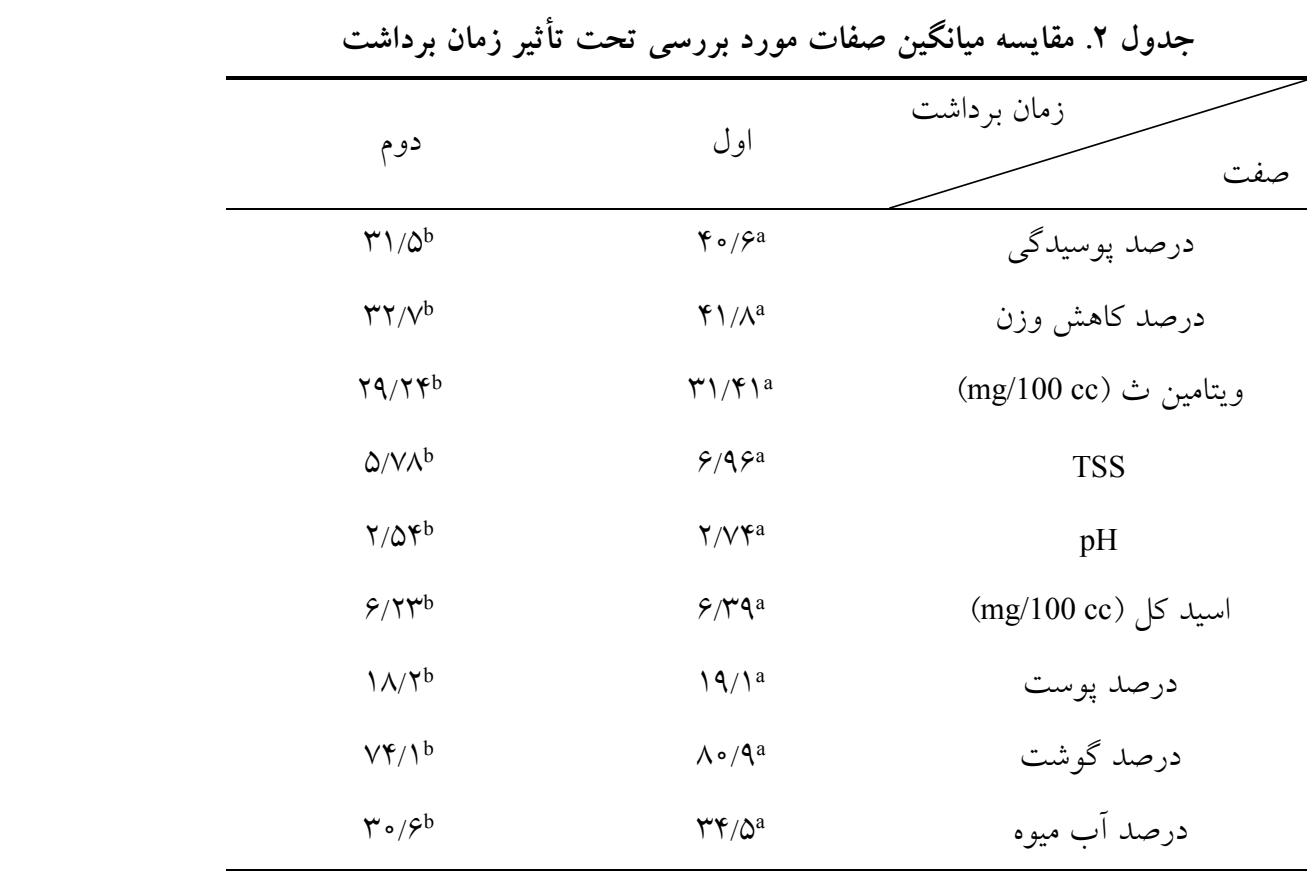

ميانخينهاى موجود در هر رديف كه حداقل داراى يك حرف مشترى هستند، در سطح يك درصد از آزمون دانكن اختلاف معنى دارى باهم ندارند.

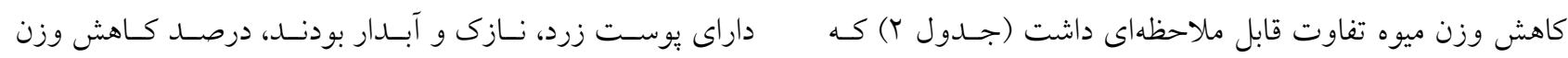

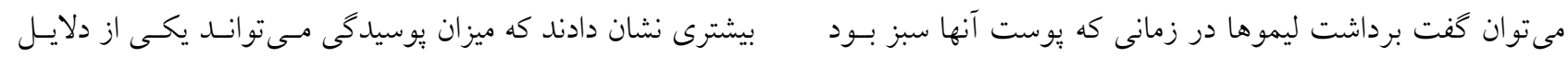

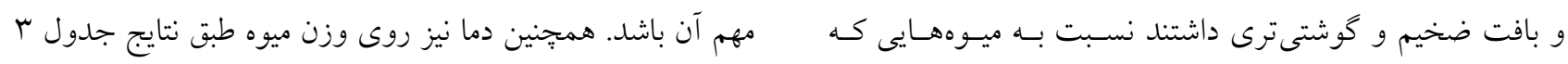


جدول r. مقايسه ميانكين صفات مورد بررسى تحت تأثير دماى انبار

\begin{tabular}{|c|c|c|c|}
\hline دماى ^ درجه & دماى ب درجه & 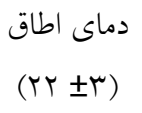 & دماى انبا \\
\hline $01 / 9^{a}$ & $1 \Lambda / T^{c}$ & $\Gamma \wedge / l^{b}$ & درصد يوسيدگى \\
\hline$\Delta r / T^{a}$ & $19 / 0^{\mathrm{c}}$ & $r q / r^{b}$ & درصد كاهش وزن \\
\hline$r Q / Q \Lambda^{c}$ & $\mu y / 4\rangle^{a}$ & $r_{\circ} / \Delta \Lambda^{b}$ & ويتامين ث (mg/100 cc) \\
\hline $9 / \Lambda^{\mathrm{b}}$ & $\mathrm{V} / 9 \mathrm{Ya}^{\mathrm{a}}$ & $\Delta / 1 Y^{c}$ & TSS \\
\hline$r / 9)^{\mathrm{a}}$ & $r / V I^{b}$ & $r / \mu I^{c}$ & $\mathrm{pH}$ \\
\hline $9 / 01^{\mathrm{c}}$ & $9 / \mathrm{V}^{\mathrm{a}} \mathrm{a}$ & $9 / T Y^{b}$ & اسيد كل (mg/100 cc) \\
\hline$T Y / T^{\mathrm{a}}$ & $1 \mathrm{~V} / \mathrm{q}^{\mathrm{b}}$ & $10 / 9^{c}$ & درصد يوست \\
\hline $\mathrm{V} / \mathrm{A}^{\mathrm{b}}$ & $\Lambda r / \Lambda^{a}$ & $V T / \Delta^{c}$ & درصد گوشت \\
\hline$m \mid / 4 b$ & $r \Delta / \wedge^{a}$ & $\mu_{\circ / 4 b}$ & درصد آب ميوه \\
\hline
\end{tabular}

زوال ميوه مركبات، از دسـت دادن آب يوسـت ميسوه و يُزمـرده

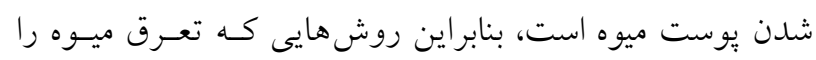

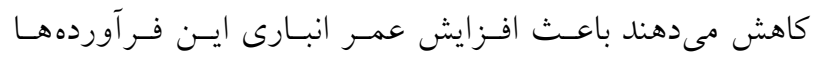

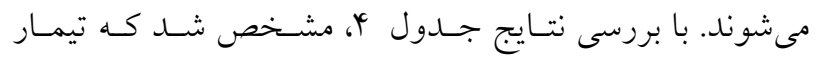

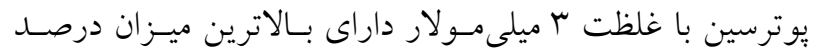

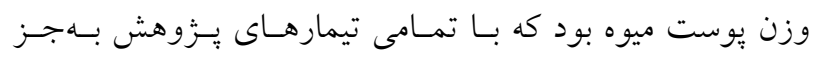

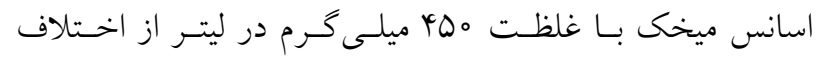

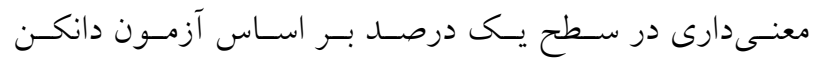

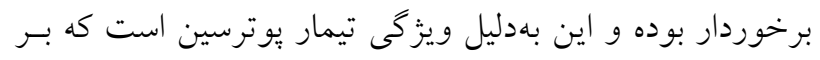

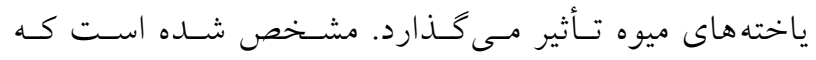

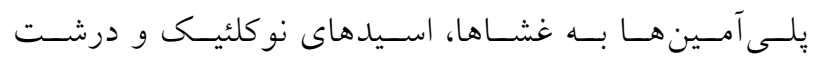

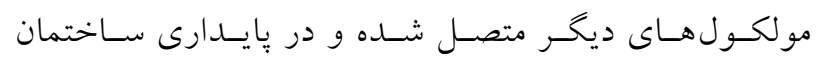

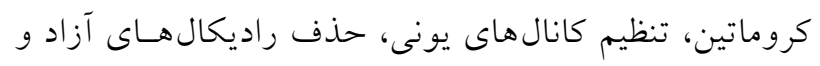

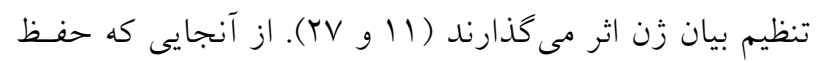

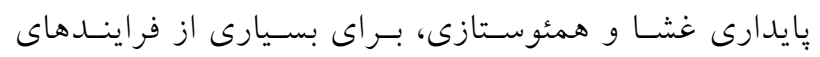

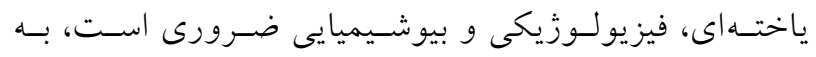

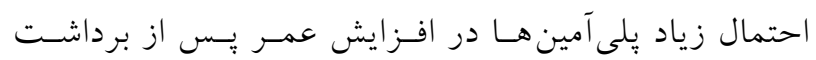

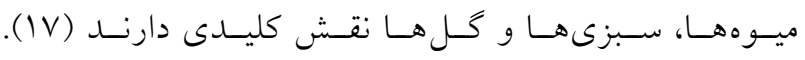

مؤثر بوده است بهطورى كه كمتـرين درصــ كـاهش وزن ميـوه در

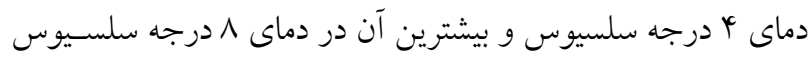

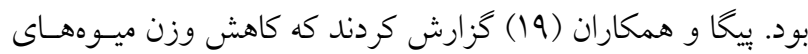
مركبات بر اثر از دست دادن آب در دوره انباردارى بستـى زيـادى

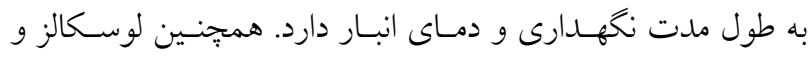
همكاران (Q) كزارش كردند كه ميزان كاهش وزن ميوههـا در دوره انباردارى در رقمهاى مختلف مركبات تفاوت معنى دارى دارد.

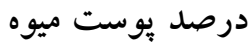

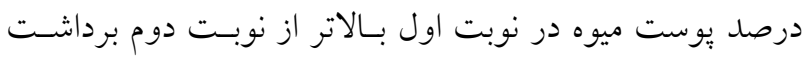

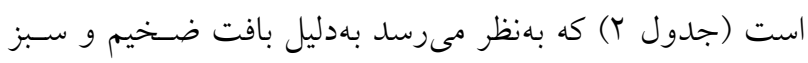

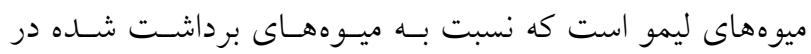

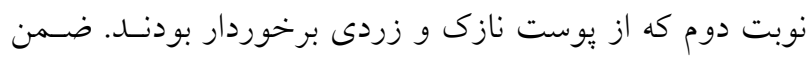
اينكه درصد وزن بوست ميوهها تحــت تـأثير دمـاى انبـار قـرار

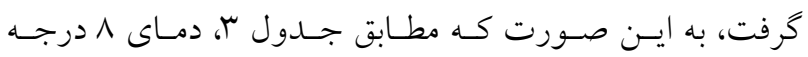

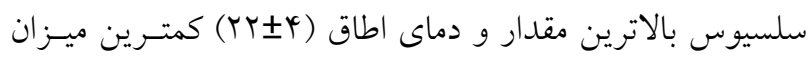

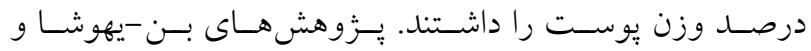

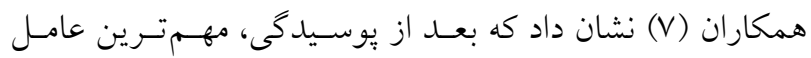




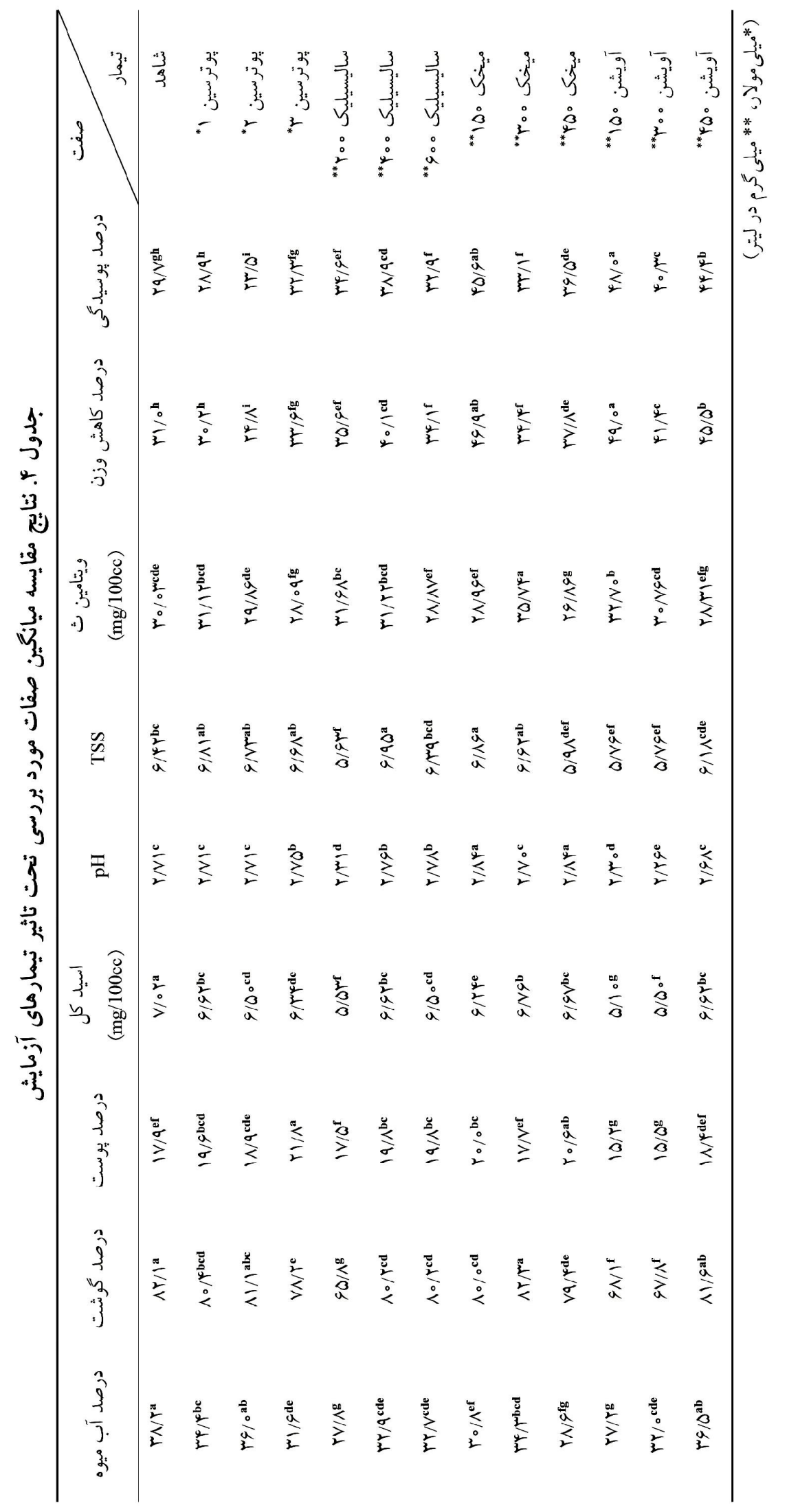


يكديخر از اختلاف معنى دارى در سطح يـى درصـــ برخـوردار

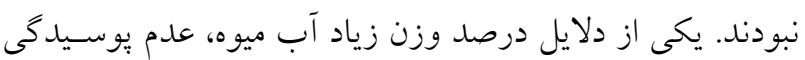

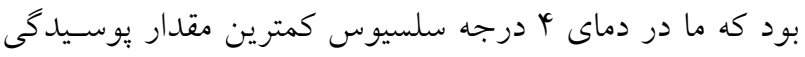

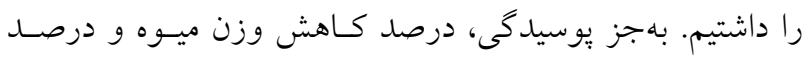

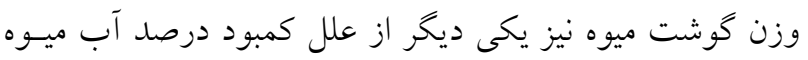

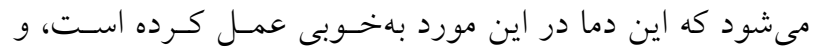
ميزان درصد كوشت ميـوه و درصـد كـاهش وزن كـل ميسوه در

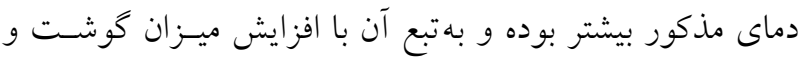

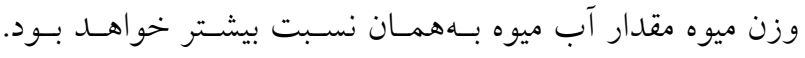
همجنين طبق جدول tا، بهترين عملكرد را تيمار شاهد داشت و

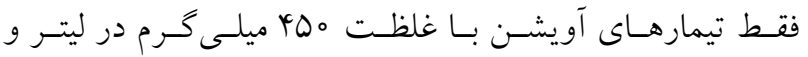

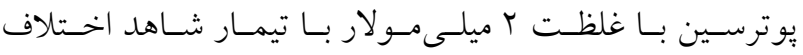
معنى دارى را در سطح يكى درصد بر اساس آزمون دانكن نشـان ندادند اما بقيه تيمارها روى درصد آب ميوه تـأثيرى نداشـتند و نتوانستند در ميزان آب ميوه ايفاى نقش مثتسى را داشـته باشــند.

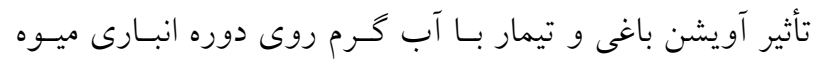

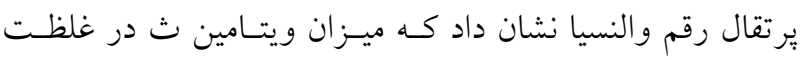

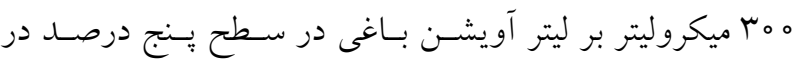
مقايسه با ميوههاى شاهد معنى دار بود (9).

ميزان مواد جامد محلول (TSS) نوبت اول داراى ميزان مواد جامد محلول (TSS) بيشترى نسبت به مرحله دوم برداشت بـود كـه ايسن تفـاوت معنسىدارى را در سطح يكى درصد طبق آزمون دانكن نشان داد (جدول باد ب). بهطور كلى افزايش مواد جامد محلول با كذشت زمان مىتواند ناشى از

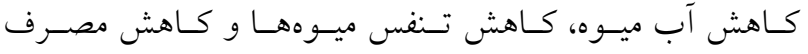
كربوهيدراتها باشد. بر اساس نتايج جدول كا، بيشترين ميـزان

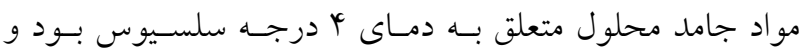
كمترين ميزان آن بهترتيب متعلق به دماى اطاق و دماى ^ درجهـ

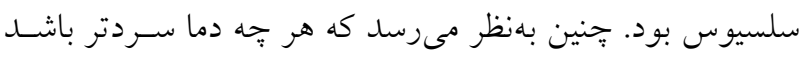

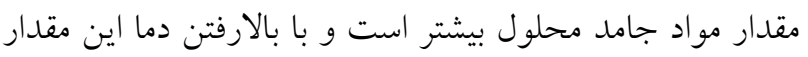

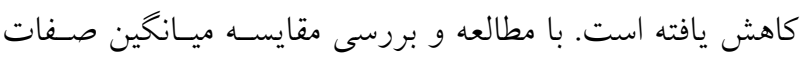

بلديهى است كاهش وزن ميوه طى دوره انباردارى نتيجـه تبخيـر آب از سطح ميوه است.

درصد گوشت ميوه نوبت اول برداشت، از Y درصد وزن كوشت بيشترى نسـبت بـهـ نوبت دوم برخـوردار بـود (جـــول r) جـــا كـه در نوبـت اول ميوههاى سبز و كوشـتى را برداشـت كـرديم امـا در نوبـت دوم برداشت ميوههاى زرد جيده شد و جون ميوههاى سـبز از بافت ضخيم و كوشتى ترى برخوردار بودند بههمين دليل وزن كوشت نئس

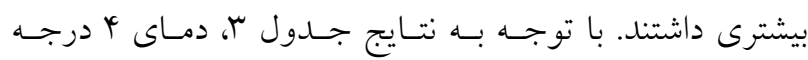
سلسيوس بيشترين مقدار وزن كوشت را داشت و كمترين ميزان آن متعلق به دماى اطاق بود. همجنين طبق نتايج جدول با تيمـار

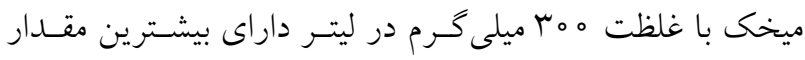

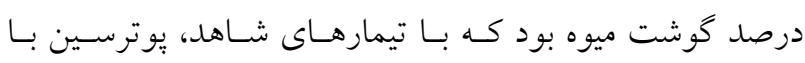

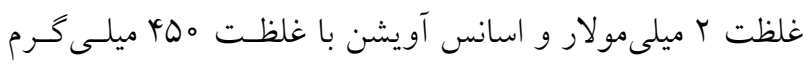

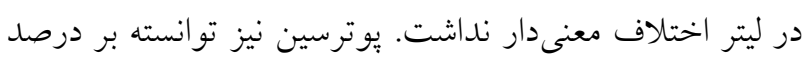

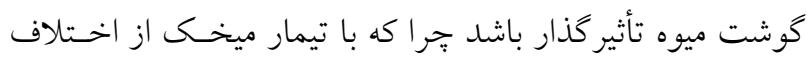

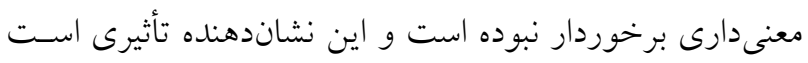

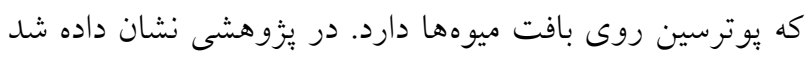

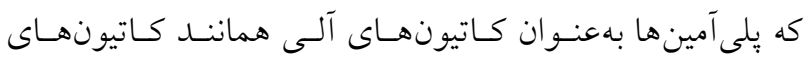

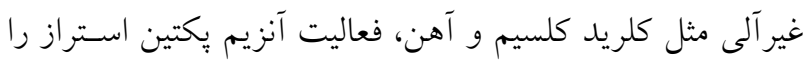

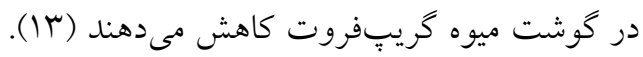
درصد آب ميوه نوبت اول برداشت از ميزان درصد آب بيشترى نسبت به نوبـت

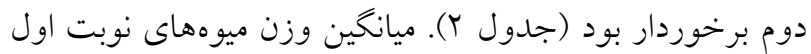

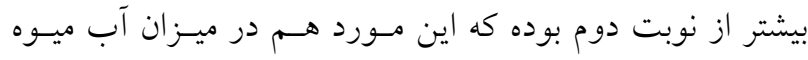

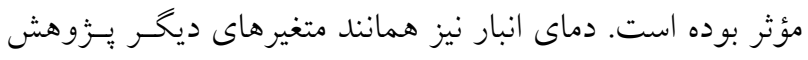

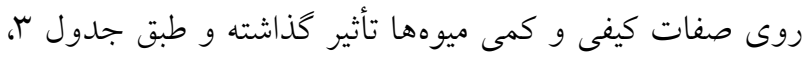

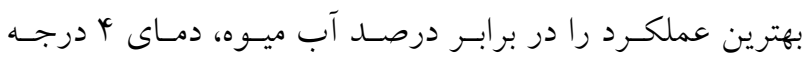
سلسيوس داشت. پِ از آن دماى ^ درجه سلسيوس و در آخـر

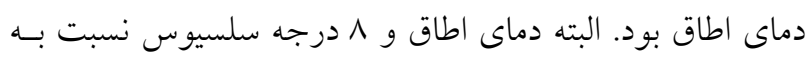


بودهه و مى تواند دليلى بر كـاهش pH و خاصسيت اسـيدى ليمـو

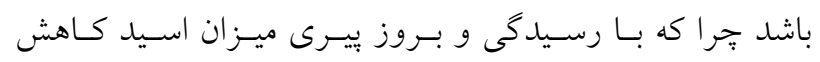

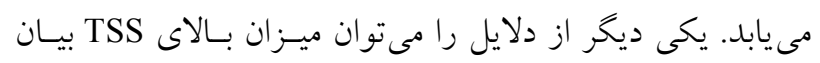

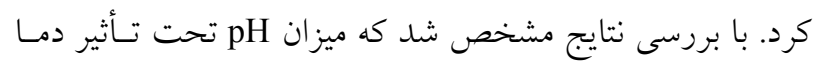

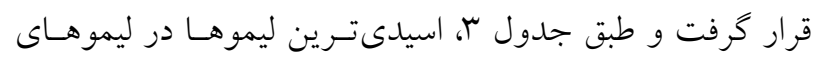

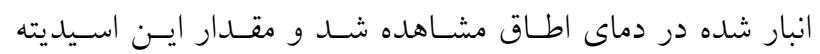

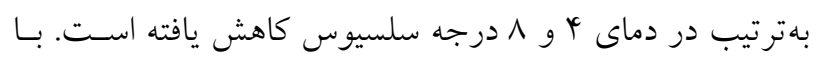

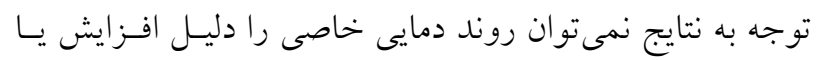

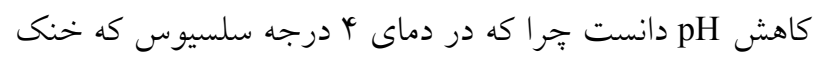

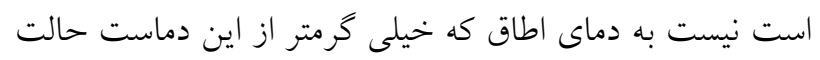

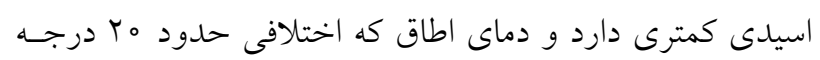

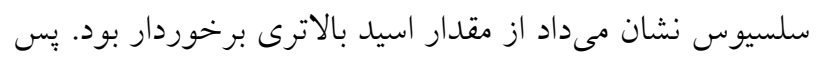
نمودار دمايى اين قسمت از يُزوهش سير ثـابتى نداثـته و ابتــدا

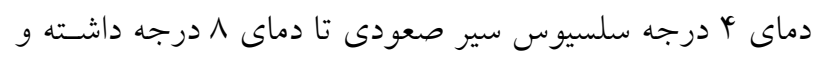

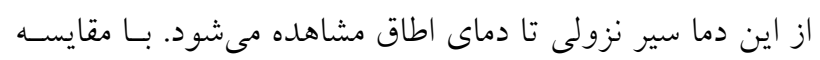

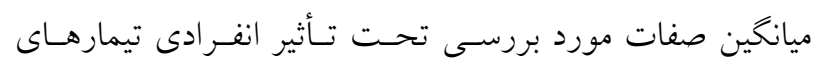

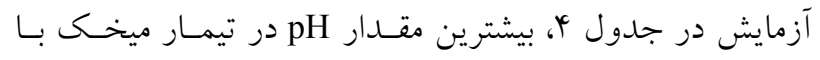

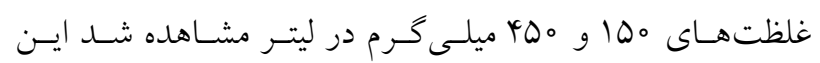

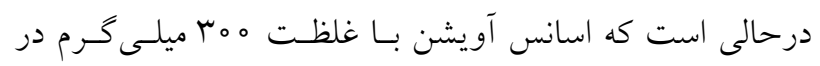

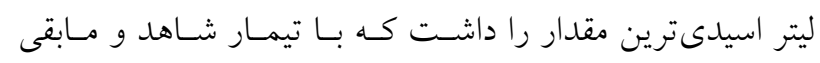
تيمارها اختلاف معنى دارى در سطح يكى درصد آزمسون دانكـن تئن

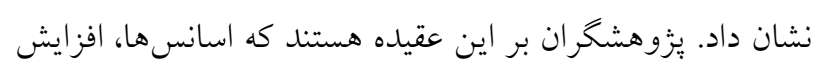

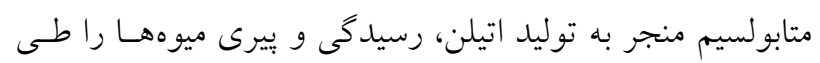

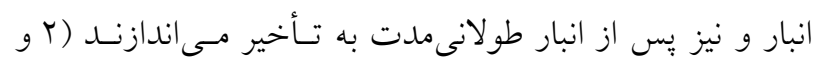

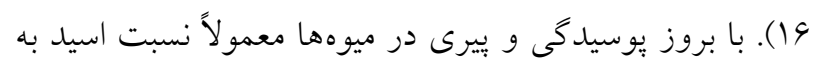

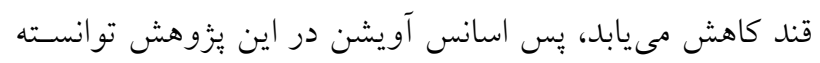

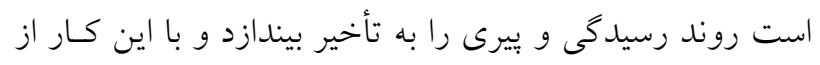
تبديل اسيدهاى آلى ميوه به قند جلو گيرى بهممل آورد و و مقـدار

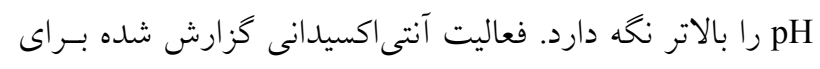

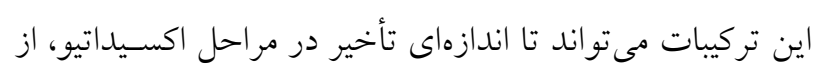

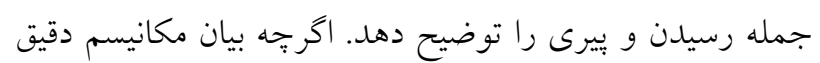
أنها تحقيقات بعدى را مى طلبد.
مورد بررسى تحت تأثير اثر انفــادى تيمارهـاى آزمـايش طبـق

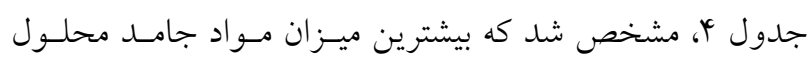

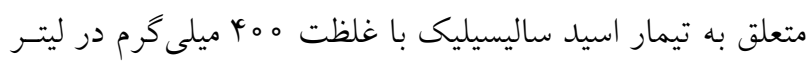

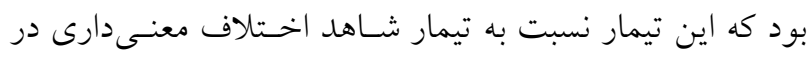

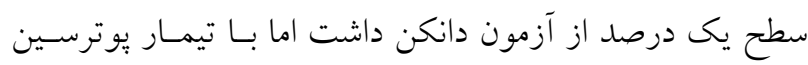

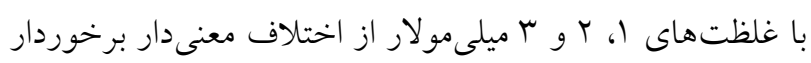

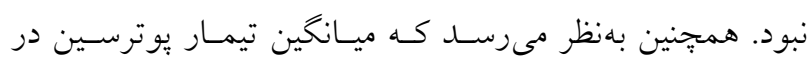

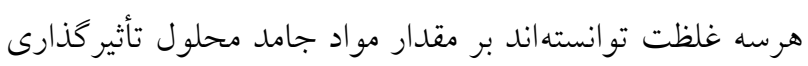

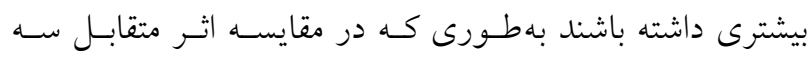

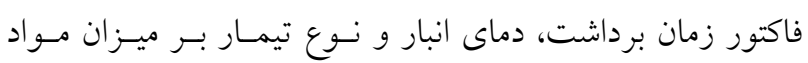

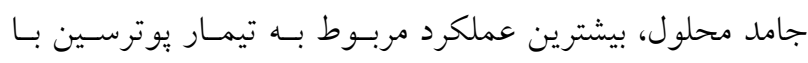

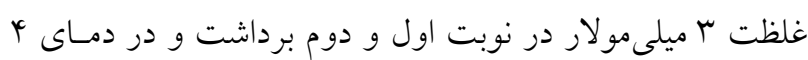

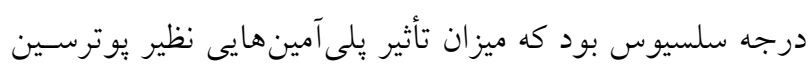

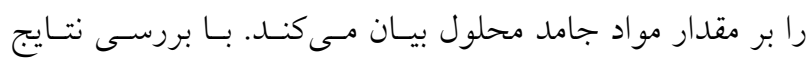

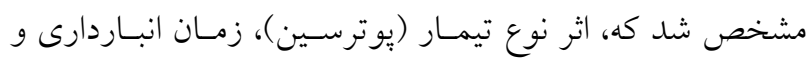

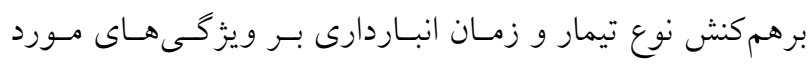

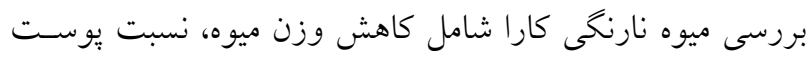

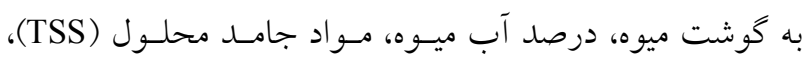

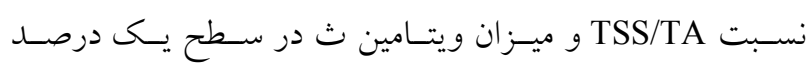
معنى دار و روى pH و اسيديته قابل تيتراسـيون (TA)، معنسى دار

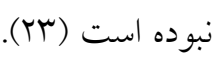

\section{pH}

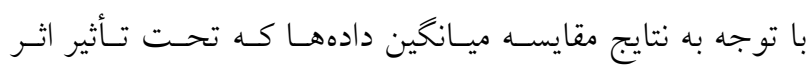

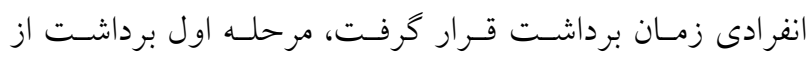

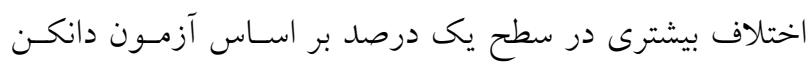

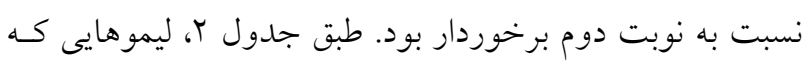

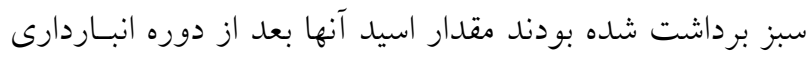
كاهش يافته بود درحالى كه ليموهاى نوبت دوم كه زرد و كاملاً

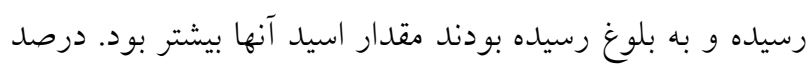

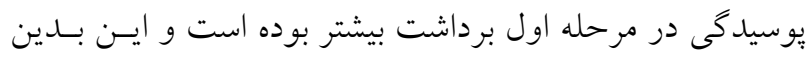

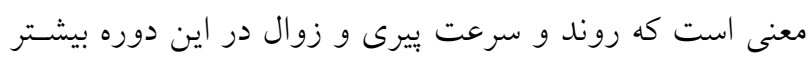


بيشتر است. در يززوهشى با كـاربرد واكس، كـاهش كمتـرى در مقدار ويتامين (ث) ميوههاى نارنخى كينو مشاهده شـــ احتمـال

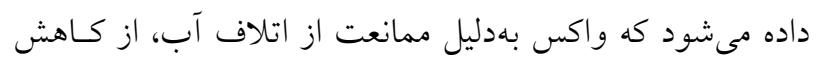

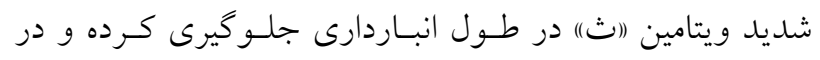

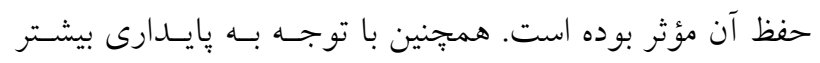

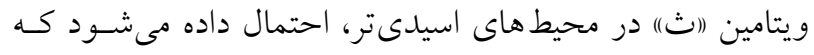
تيمار واكس در حفظ شرايط اسيدى ميوه و كمك به حفظ اسيد

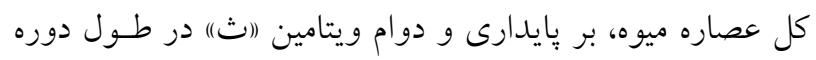

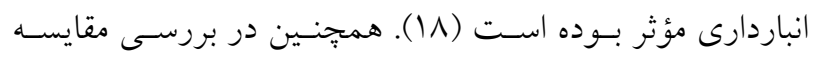

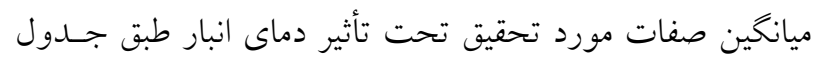

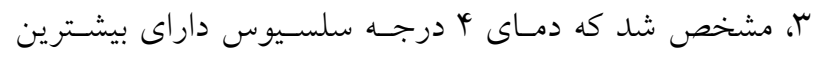

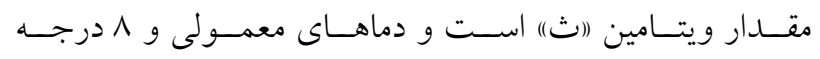

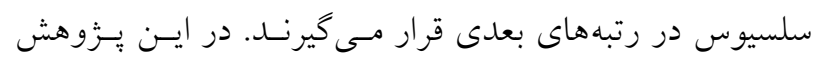

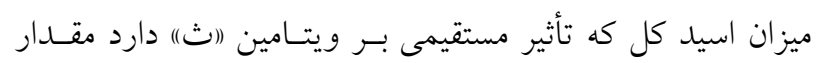
بيشترى داشت. نشان داده شده كه ميزان ويتـامين (اث) در ميـوه

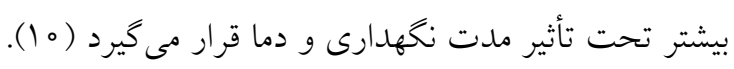

\section{درصد بوسيدگى} درصد يوسيدكى در نوبت اول بالاتر از مرحله دوم برداشت بود

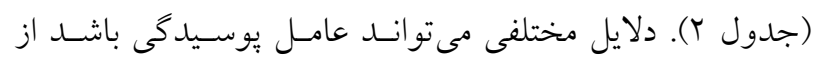

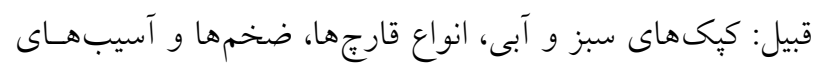

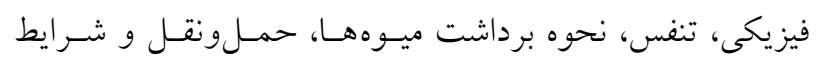

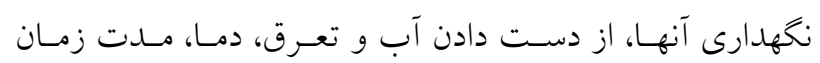

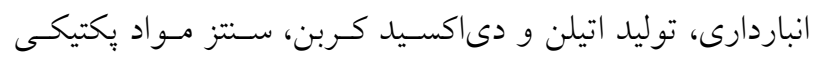

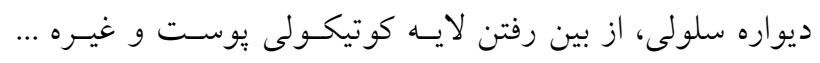

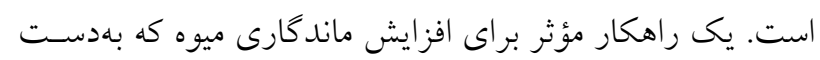

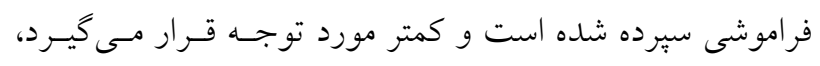

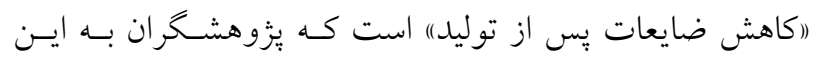

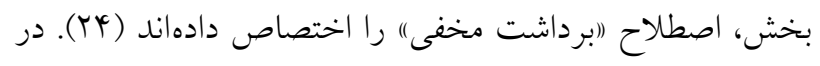

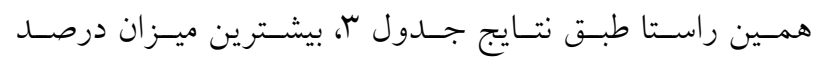

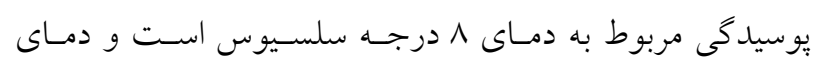

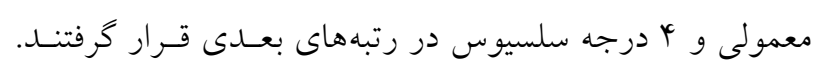

ميزان اسيد كل قابل تيتراسيون (TA) بر اساس نتايج مقايسه ميـانخين دادههـا كـهـ تحــت تـأثير زمـان

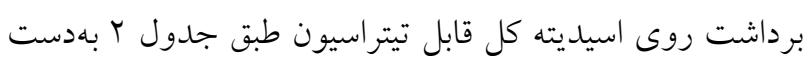

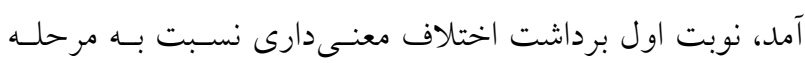

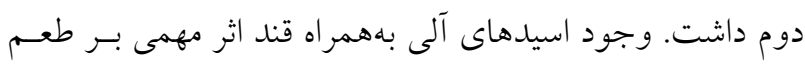

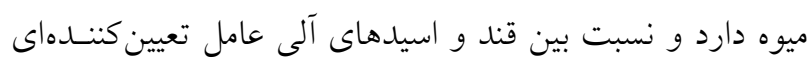

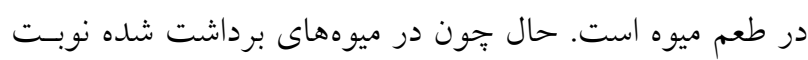

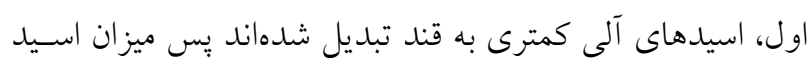

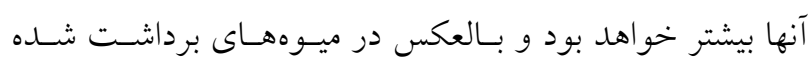
نوبت دوم ميزان اسيد كاهش يافته و مصرف شده اسـت، مقــدار

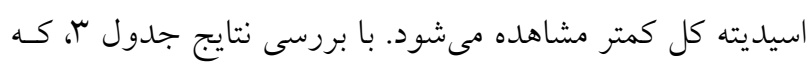

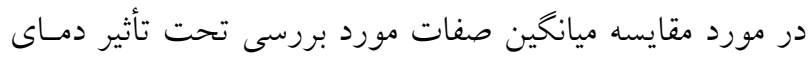

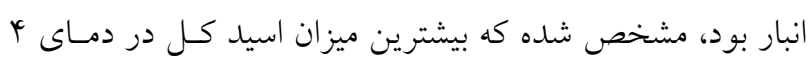

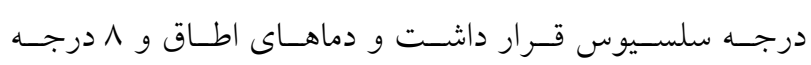

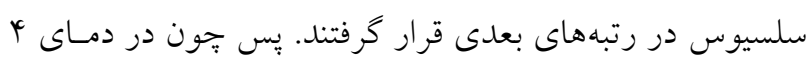

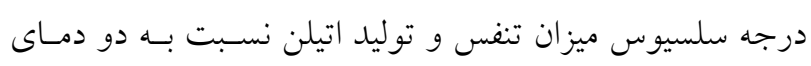
ديخر به حداقل مىرسد و اسيد كمترى مصرف مى شوده، بنابراين

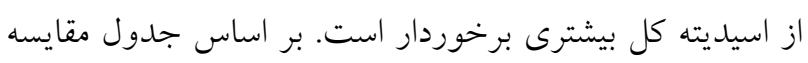
ميانخين صفات مورد بررسى تحت تـأثير اثـــ انفـرادى تيمارهـا

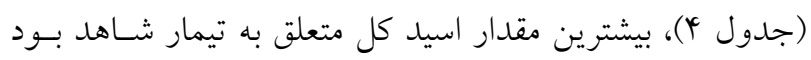

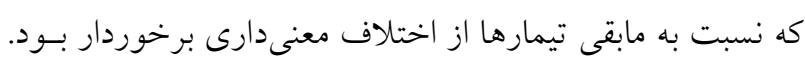

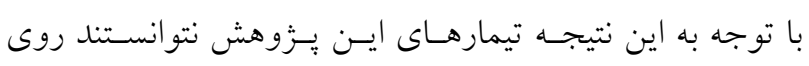

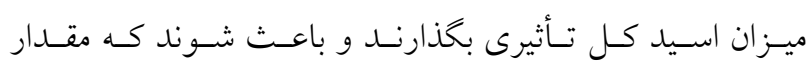

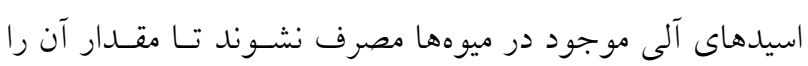
بالاتر از تيمار شاهد نخه دارند.

ميزان ويتامين ث

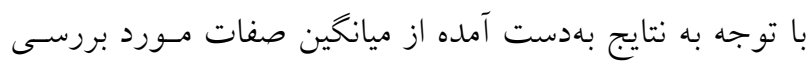

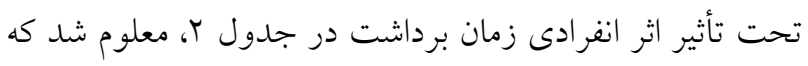

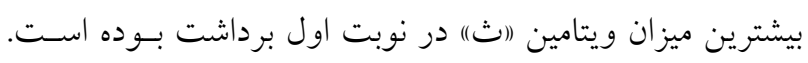

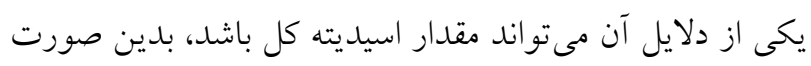

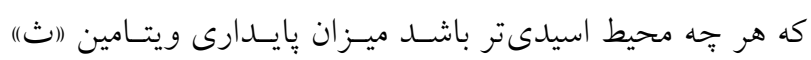




$$
\begin{aligned}
& \text { دما يكى از عوامل مهم در ميـزان يوسـيدگى اسـت كـهـهـم در سفتى آن مىشود. نتايج بزوهش ما با نتايج رمضانيان و همكاران }
\end{aligned}
$$

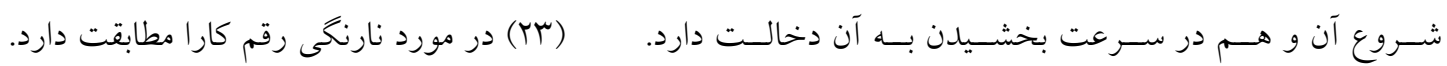

$$
\begin{aligned}
& \text { سرمازدگى و صدمه ديدن بافت ميـوههـا يكسى ديخـــ از دلايـل }
\end{aligned}
$$

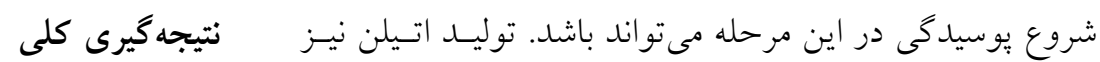

$$
\begin{aligned}
& \text { بهطور كلى بيشترين تأثير در ميان تمامى تيمارها، كاربرد يسس از } \\
& \text { يكى ديخر از عو امل بيرى و زوال ميوه و بوسـيدكى بـهـسـاب }
\end{aligned}
$$

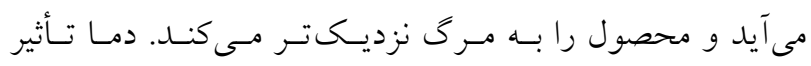

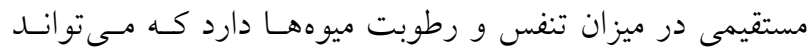

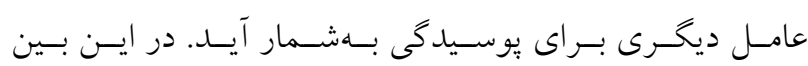

$$
\begin{aligned}
& \text { دىاكسيدكربن نيز يك عامل تعيين كننده بـهــمار مسى آيـد. بـا } \\
& \text { توجه به نتايج جدول أ، تيمار بوترسين با غلظت ب ميلى مـولار } \\
& \text { كارآمدترين تيمار بوده است و توانسته مؤثر واقع شود. يوترسين بـ بوني }
\end{aligned}
$$

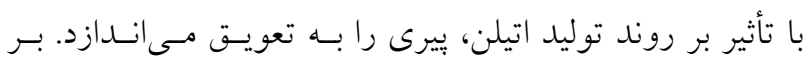

$$
\begin{aligned}
& \text { آنزيمهاى بِكتين استراز، بِكتين متيل اسـتراز و پِلسى كالاكترونـاز } \\
& \text { تأثير گذاشته و از نرم شدن بافت ميوه جلو گيرى مى كند و باعث }
\end{aligned}
$$

\section{منابع مورد استفاده}

1. Aboutalebi, A. H. and M. H. Mohammadi. 2011. Effect of essential oils on postharvest stability of fruits quality and decay management of Kinnow Mandarin. Journal of Seed and Plant Production 27: 501-504. (In Farsi).

2. Almenar, E., V. D. Valle, R. Catala and R. Gavara. 2007. Active package for wild strawberry fruits (Fragaria vesca L.). Journal of Agriculture and Food Chemistry 55: 2240-2245.

3. Angioni, A., A. Barra, E. Cereti, D. Barile, J. D. Coisson and M. Arlorio. 2004. Chemical composition, plant genetic differences, antimicrobial and antifungal activity investigation of the essential oil of Rosmarinus officinalis L. Journal of Agricultural Food Chemistry 52: 3530-3535.

4. Anthony, S., K. Abeyvikrama and W. S. Wilson. 2003. The effect of spraying essential oils of Cymbopogon nardus, Cymbopogon flexuosus and Ocimum basilicum on postharvest diseases and storage life of Embul banana. The Journal of Horticultural Science and Biotechnology 78(6): 780-785.

5. Arras, G. and M. Vsai. 2001. Fungi toxic activity of 12 essential oils agai ${ }^{\text {ns }}$ t four postharvest citrus pathoge ${ }^{\text {nss: }}$ chemical analysis of Thymus capitates oil and its effect in sub atomospheric pressure condition. Journal of Food Protection 4(7): 1025-1029.

6. Babala, M., M. Asghari, A. Talaei and A. Khosroshahi. 2007. Effect of pre and postharvest salicylic acid treatment on ethylene production, fungal decay and overall quality of Selva strawberry fruits. Food Chemistry 105: 449-453.

7. Ben-Yehoshua, S., B. Shapiro and R. Moran. 1987. Individual seal-packaging enables the use of curing at high temperatures to reduce decay and heal injury of citrus fruits. Hort Science 22: 777-783.

8. Casero, R. A. and L. J. Marton. 2007. Targeting polyamine metabolism and function in cancer and other hyper proliferative diseases. Nature Reviews Drug Discovery 6: 373-390.

9. Fatemi, S., M. Jafarpour and Sh. Eghbalsaeid. 2011. Study of the effect of Thymus vulgaris and hot water treatment on storage life of orange (Citrus sine ${ }^{n s}$ is cv. Valencia). Journal of Medicinal Plants Research 6(6): 968-971.

10. Hayat, I., T. Masud and H. A. Rathore. 2005. Effect of coating and wrapping materials on the shelf life of apple (Malus domestica cv. Borkh). International Journal of Food Safety 5: 24-34.

11. Karasahin, I., M. Pekmezci and M. Erkan. 2005. Combined hot water and uv-c treatments reduces postharvest decay and maintai ${ }^{\text {ns }}$ quality of eggplants. Postharvest Technology 5: 11-18.

12. Karimi, Z. and M. Rahemi. 2008. Comparison of essential oils of clove, thyme and Imazalil fungicide on blue mold (Penicillium italicum Wehemer) of citrus fruits in storage. Journal of Science and Technology of Agriculture and Natural Resources 12(45): 231-237. (In Farsi). 
13. Leiting, V. A. and L. Wicher. 1997. Inorganic captions and polyamines moderate pectin esterase activity. Journal of Food Science 62(2): 253-255.

14. Leslie, C. A. and R. J. Romani. 1998. Inhibition of ethylene biosynthesis by salicylic acid. Plant Physiology 88: 837-833.

15. LoScalzo, R., T. Innoccari, C. Summa, R. Morelli and P. Rapisarda. 2004. Effect of thermal treatment on antioxidant and antiradical activity of blood orange juice. Food Chemistry 85: 41-47.

16. Martinez-Romero, D., S. Castillo, J. M. Valverde, F. Guillen, D. Valero and M. Serrano. 2005. The use of natural aromatic essential oil helps to maintain postharvest quality of crimson table grapes. Acta Horticulture 682: 17231729.

17. Paliyath, G., D. P. Murr, A. K. Handa and S. Lurie. 2008. Postharvest Biology and Technology of Fruits, Vegetables, and Flowers. Wiley-Blackwell Publish.

18. Panah, Z., M. Honarvar and A. Aboutalebi. 2012. Effect using Chitin seal wax on postharvest life of Kinnow mandarin. Postharvest Physiology and Technology of Horticultural Crops 1: 101-109.

19. Piga, A. D., S. Aquino and M. Agabbio. 2000. Influence of cold storage and shelf-life on quality of 'Salustiana' orange fruits. Fruits 55: 37-44.

20. Plaza, P., R. Torres, J. Usall, N. Lamarca and I. Vinasa. 2004. Evaluation of the potential of commercial postharvest application of essential oils to control citrus decay. Journal of Hortcultural Science and Biotechnology 79(6): 936-940.

21. Ponce, A. G., C. E. Valle and S. L. Roura. 2004. Natural essential oils as reducing agents of peroxidase activity in leafy vegetables. Journal of Food Science and Technology 37: 199-204.

22. Rahemi, M. 2007. Postharvest physiology: Introduction to physiology and handling of fruit and vegetables. Shiraz University Publications.

23. Ramazanian, A., F. Khoram and A. Ahmadpour. 2015. Effect of wax coating and different concentration of putresin on qualitative and quantitative characteristics Kara mandarin fruits during storage time. Plant Production 38(4): 6170. (In Farsi).

24. Ranjbaran, E., H. Sarikhani, D. Bakhshi and P. Mehrdad. 2011. Investigation of salicylic acid application to reduce postharvest losses in Stored 'Bidaneh Ghermez' table grapes. International Journal of Fruit Science 11: 430-439.

25. Raskin, I. 1992. Role of salicylic acid in plants. Annual review of plant physiology. Plant Molecular Biology 43: 439-463.

26. Srivastava, A., S. H. Chung, T. Fatima, T. Datsenka, A. K. Handa and A. K. Mattoo. 2007. Polyamines as anabolic growth regulators revealed by tra ${ }^{\text {ns }}$ cript me analysis and metabolite profiles of tomato fruits engineered to accumulate spermedine and serine. Plant Biotechnology 24: 57-70.

27. Srivastava, M. K. and U. N. Dwivedi. 2000. Delayed ripening of banana fruit by salicylic acid. Plant Science 158: 87- 96.

28. Torrigiani, P., A. M. Bregoli, V. Ziosi, S. Scaramagli, T. Ciriaci, A. Rasori, S. Biondi and G. Costa. 2004. Preharvest polyamine and aminoethoxy vinyl glycine (AVG) applications modulate fruit ripening in Stark Red Gold nectarines (Prunus persica L. Batsch). Postharvest Biology and Technology 33: 293-308.

29. Tsigarida, E., P. Skandamis and G. J. Nychas. 2000. Behaviour of Listeria monocytogenes and Autochthonous floraonmeat stored under aerobic, vacuum and modified atmosphere packaging conditions with or without the presence of oregano essential oil at 5 degrees. Journal of Applied Microbiology 89(6): 901-909.

30. Wang, L., S. Chen, W. Kong, S. Li and D. D. Archbold. 2006. Salicylic acid pretreatment alleviates chilling injury and affects the antioxidant system and heat shock proteins of peaches during cold storage. Postharvest Biology and Technology 41: 244-251. 


\title{
Effect of Harvest Time, Non-Toxic Treatments and Storage Temperature on Postharvest Life of Mexican Lime (Citrus aurantifolia L.)
}

\author{
A. Hatami ${ }^{1}$ and A. H. Aboutalebi Jahromi ${ }^{*}$
}

(Received: November 10-2018; Accepted: June 08-2020)

\begin{abstract}
In order to evaluate the effect of harvesting time, storage temperature and non-toxic treatments of Putrescine $(\mathrm{Pu})$, salicylic acid (SA) and thyme and cloves essential oils (TEO and CEO) on qualitative and quantitative characteristics of Mexican lime fruit, a factorial completely randomized design experiment was performed. This experiment was conducted with three storage temperature levels including ambient temperature $\left(22 \pm 3^{\circ} \mathrm{C}\right), 4 \pm 1$ and $8 \pm 1{ }^{\circ} \mathrm{C}$, and the treatments including $\mathrm{Pu}(1,2$ and $3 \mathrm{mmol})$, SA (200, 400 and $600 \mathrm{mg} / \mathrm{l})$, TEO and CEO (150, $300 \mathrm{and} 450 \mathrm{mg} / \mathrm{l})$ and distilled water as control treatment. The fruits were harvested in two stages including the maturity stage (early color change) and the ripening stage (yellow color) in four replications and 10 fruits in each replication. Effects of harvesting time, storage temperature and treatment type on fruit quality attributes were significant $(\mathrm{p}<0.01)$. It was found that the green harvesting stage is the best time for harvesting. It was further found that storing at temperatures above $4{ }^{\circ} \mathrm{C}$ is the most effective temperature in increasing the postharvest life of Mexican lime fruits. It was also found that the 2 and 3 mmol Pu applications can be used to preserve and maintain the Mexican lime fruits.
\end{abstract}

Keywords: Mexican lime, Postharvest, Salicylic acid, Putrescine, Essential oils

1, 2. Masters Student and Associate Professor, Respectively, Horticultural Groups, Jahrom Branch, Islamic Azad University, Jahrom, Iran.

*: Corresponding Author, Email: aa84607@gmail.com 